\title{
Minimization of interface roughness in laser deposited Fe/MgO multilayers
}

\author{
Andreas Meschede · Hans-Ulrich Krebs
}

Received: 13 July 2010 / Accepted: 17 August 2010 / Published online: 22 September 2010

(C) The Author(s) 2010. This article is published with open access at Springerlink.com

\begin{abstract}
The physical properties of multilayers with layer periods in the nanometer range crucially depend on the nature of their interfaces. In this contribution we show how the interfacial roughness of multilayers consisting of two materials with a high difference in specific surface free energy (here $\mathrm{MgO} / \mathrm{Fe}$ ) and thus different growth modes (VolmerWeber island growth for Fe and layer-by-layer growth for $\mathrm{MgO}$ ) can be minimized. For this, the layer thickness of the island former has to be large enough that almost all island zipping processes have already occurred. At this thickness the layer is just closed and the intrinsic roughness is at a minimal value. To determine this optimal thickness, insitu stress measurements as performed in this work are one method of choice. The layer-by-layer growth of the other material with lower surface free energy additionally leads to a further smoothening of the surface. Due to this alternating roughening and smoothing processes, cumulative roughness can be avoided and overall a minimal roughness of the multilayer structure is obtained.
\end{abstract}

\section{Introduction}

The physical properties of multilayers with small layer periods in the nanometer range crucially depend on the nature of their interfaces [1]. Assuming a Gaussian distribution of interface roughness (and intermixing, which cannot be distinguished in X-ray reflectometry), the reflectivity $R$ of a multilayer mirror is critically attenuated by the fraction of

A. Meschede · H.-U. Krebs ( $\varangle)$

Institut für Materialphysik, Georg-August-University

of Göttingen, Friedrich-Hund-Platz 1, 37077 Göttingen, Germany

e-mail: krebs@ump.gwdg.de

Fax: +49-551-395012 its roughness $\sigma$ compared to its bilayer period $\Lambda$ according to

$R=R_{0} e^{-\left(\frac{2 \pi \sigma}{\Lambda}\right)^{2}}$

where $R_{0}$ is the reflectivity of a perfect multilayer with discrete interfaces. When working in the soft X-ray region, as in the so-called water window (wavelength range $\lambda=2.3$ $4.4 \mathrm{~nm}$ ), small layer periods below $4 \mathrm{~nm}$ are necessary, which dramatically increases the importance of a low interface roughness.

$\mathrm{MgO} / \mathrm{Fe}$ multilayers are promising candidates for X-ray mirrors in the water window due to their high thermal stability [2] and good optical contrast. But, in recent years, layered $\mathrm{Fe} / \mathrm{MgO}$ systems are also of special interest due to tunnel magnetoresistance (TMR) values up to $250 \%$ achieved in $\mathrm{Fe} / \mathrm{MgO} / \mathrm{Fe}$ trilayers [3]. In this materials combination the growth of $\mathrm{Fe}$ on $\mathrm{MgO}$ is different from $\mathrm{MgO}$ growth on $\mathrm{Fe}$ due to the large difference of the surface energies of $\mathrm{Fe}\left(2.9 \mathrm{~J} / \mathrm{m}^{2}\right)$ and $\mathrm{MgO}\left(1.16 \mathrm{~J} / \mathrm{m}^{2}\right)$, respectively [4]. From this large difference in the surface energies layer-by-layer growth is favored for $\mathrm{MgO}$ on $\mathrm{Fe}$ but not vice versa. Instead, Fe grows in Volmer-Weber island mode [5] at room temperature.

In this paper, the interfaces of laser deposited $\mathrm{Fe} / \mathrm{MgO}$ layered structures were studied. In the $\mathrm{MgO} / \mathrm{Fe}$ system with Volmer-Weber island growth mode of one component $(\mathrm{Fe})$, the roughness of the $\mathrm{MgO} / \mathrm{Fe}$ interface (here $\mathrm{MgO} / \mathrm{Fe}$ means $\mathrm{MgO}$ on top of $\mathrm{Fe}$ ) should depend especially on the state of the island growth. The second layer material $(\mathrm{MgO})$ should have layer-by-layer growth and additionally smoothen the surface again. It is of interest, whether and at which layer thickness of $\mathrm{Fe}$ in $\mathrm{Fe} / \mathrm{MgO}$ multilayers a minimal roughness is obtained. 


\section{Experimental details}

For the deposition of the multilayers, a standard pulsed laser deposition setup was used [6]. KrF excimer laser pulses (Lambda Physik LPX 110i, wavelength 248 nm, pulse duration $30 \mathrm{~ns}$ ) were focused onto the elemental (Fe) or composite $(\mathrm{MgO})$ targets. The background pressure within the deposition chamber was better than $5 \times 10^{-8}$ mbar. The $\mathrm{Fe} / \mathrm{MgO}$ multilayers were deposited at room temperature onto $\mathrm{Si}(111)$-substrates (with about $2 \mathrm{~nm}$ native $\mathrm{SiO}_{2}$ on top) at a target-to-substrate distance of $7 \mathrm{~cm}$ and a laser fluence of $6 \mathrm{~J} / \mathrm{cm}^{2}$. Always the starting layer on $\mathrm{Si}$ was $\mathrm{MgO}$. X-ray measurements were carried out with a Philips X'pert diffractometer using $\operatorname{Co} K_{\alpha}$-radiation. For the in-situ rate measurements, the films were deposited directly onto a micro balance quartz crystal (Leybold Inficon XTM/2). From this, the accurate film thickness could be determined. The film thickness linearly increases with the number of laser pulses with two different slopes corresponding to different deposition rates for $\mathrm{MgO}(0.01 \mathrm{~nm} /$ pulse $)$ and $\mathrm{Fe}(0.003 \mathrm{~nm} /$ pulse $)$. At the interfaces, the slopes of the straight lines change, but no deviations from the straight lines are observed. This indicates that no re-sputtering effects occur, as for instance earlier found for other laser deposited multilayer structures (for instance $\mathrm{Fe} / \mathrm{Ag}$ ) [7].

The film stress was measured using an in-situ bending beam technique as described in Ref. [8]. The bending radius $R$ of the substrate was determined from the reflections of a laser beam hitting the backside of the substrate during deposition. The stress was calculated using the Stoney equation [9]

$\sigma D_{\mathrm{f}}=\frac{E}{1-v} \frac{D_{\mathrm{S}}^{2}}{6 R}$,

where $D_{\mathrm{f}}$ means the film thickness, $E$ the Young modulus, $v$ the Poisson ratio, and $D_{\mathrm{S}}$ the substrate thickness. The product $\sigma D_{\mathrm{f}}$ of the film stress and the film thickness we will refer to as the "stress thickness".

\section{Results and discussion}

First, the structure and microstructure of the $\mathrm{MgO} / \mathrm{Fe}$ multilayers were investigated. The crystallographic orientation relation between the two components $\mathrm{Fe}$ and $\mathrm{MgO}$ was determined by X-ray diffraction. In Fig. 1 the X-ray diffraction pattern is shown for a $\mathrm{MgO} / \mathrm{Fe}$ multilayer on $\mathrm{Si}(111)$ with 60 periods of $5.2 \mathrm{~nm}$ and about equal thickness of the individual layers. $\mathrm{MgO}$ preferentially grows in (001)-direction on the $\mathrm{Si}$ surface and Fe epitaxially on $\mathrm{MgO}$, which can be recognized in the (002)-reflection of Fe. Therefore, both materials grow with the well known $\mathrm{Fe}(001)[110] / \mathrm{MgO}(001)[100]$ epitaxial relation $[10,11]$, due to a good lattice match (only

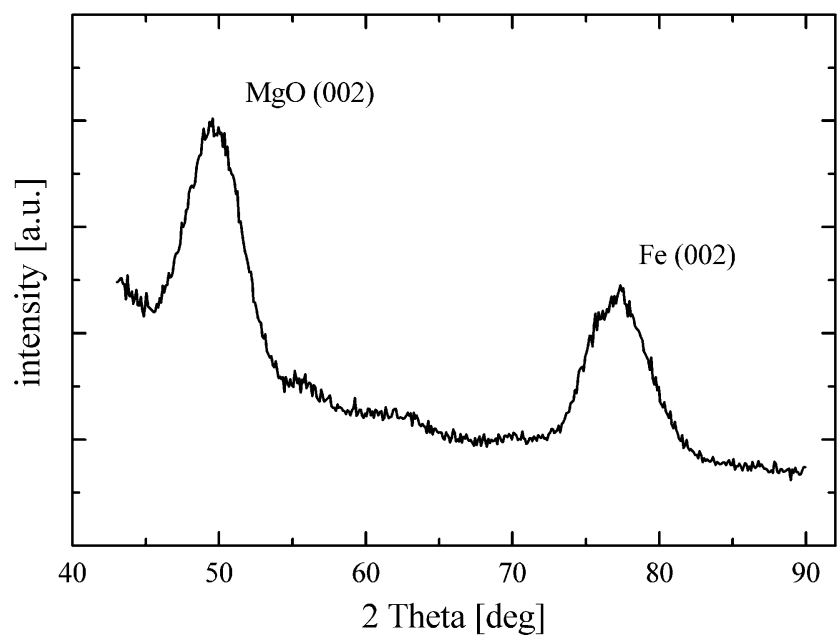

Fig. 1 X-ray diffraction pattern of a $\mathrm{MgO} / \mathrm{Fe}$ multilayer on $\mathrm{Si}(111)$ with 60 periods of $5.2 \mathrm{~nm}$ and about equal thickness of the individual layers. Both materials grow with $\mathrm{Fe}(001)[110] / \mathrm{MgO}(001)[100]$ epitaxial relation

Fig. 2 Texture measurements performed on the $\mathrm{MgO} / \mathrm{Fe}$ multilayer of Fig. 1. The intensity of the $\mathrm{Fe}(110)$ reflection was measured and is depicted for the angles $\psi$ outward $\left(0-90^{\circ}\right)$ and $\varphi\left(0-360^{\circ}\right)$ as the in-plane angle coordinate

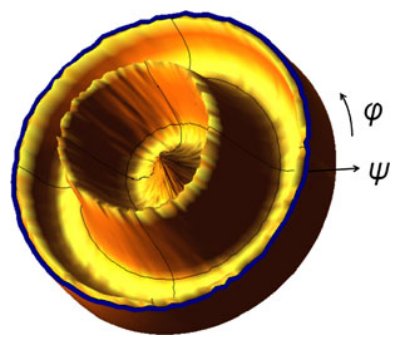

about $3.8 \%$ lattice mismatch $)$ of $\operatorname{MgO}(a=0.4213 \mathrm{~nm})$ and $\mathrm{Fe}(a=0.2866 \mathrm{~nm})$ upon a $45^{\circ}$ in-plane rotation.

On the same multilayer texture measurements were performed (see Fig. 2). The intensity of the Fe(110) reflection was measured and is depicted for the angles $\psi$ outward and $\phi$ as the in-plane angle coordinate. A fiber texture is observed. Two rings with angles of $45^{\circ}$ and $90^{\circ}$ clearly indicate that the $\mathrm{MgO}$ grains have statistical in-plane orientation although they all have a (001)-orientation in growth direction. Therefore, the observed epitaxy is only locally, what means that the $\mathrm{MgO}$ grains are randomly oriented in the film plane, but $\mathrm{Fe}$ grows epitaxially on $\mathrm{MgO}$ and vice versa. Therefore, the microstructure of the deposited multilayer is characterized by a columnar growth with random in-plane orientation as typical for sputtered or pulsed laser deposited films. But, within each column epitaxy exists.

Next we studied at which layer thickness of Fe lowest interface roughness is obtained. For this, reflectivity measurements were performed for a series of $\mathrm{MgO} / \mathrm{Fe}$ multilayers with 20 periods $\Lambda$ of between 2 and $6 \mathrm{~nm}$. In Fig. 3 the reflectivity measurements and corresponding simulations using IMD software [12] are depicted. From the simulations, the layer periodicity $\Lambda$, the ratio of metal layer thickness to bilayer period $\Gamma$ and the interface roughnesses $\sigma$ were determined. As can be seen, the decrease of the reflectivity 


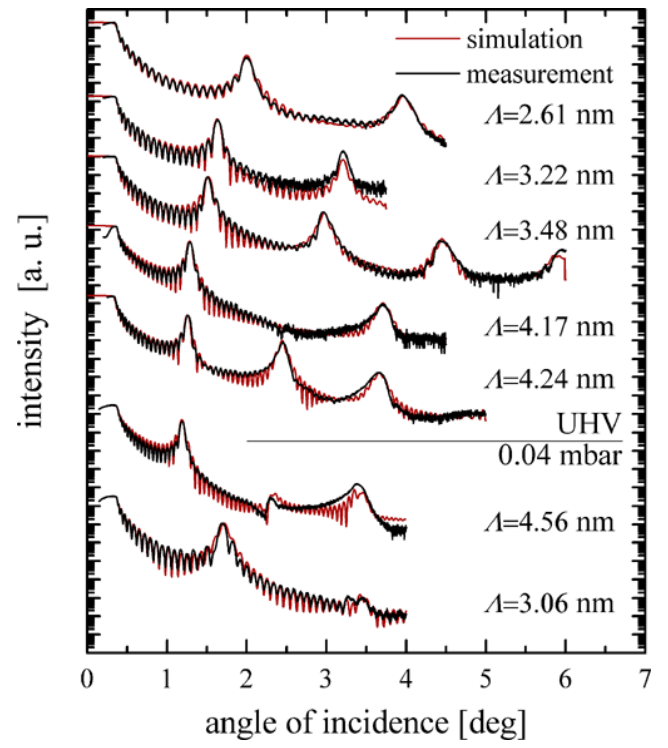

Fig. 3 Stacked X-ray diffraction patterns of $\mathrm{MgO} / \mathrm{Fe}$ multilayers with different layer periods, deposited in UHV and in 0.04 mbar Ar atmosphere, respectively

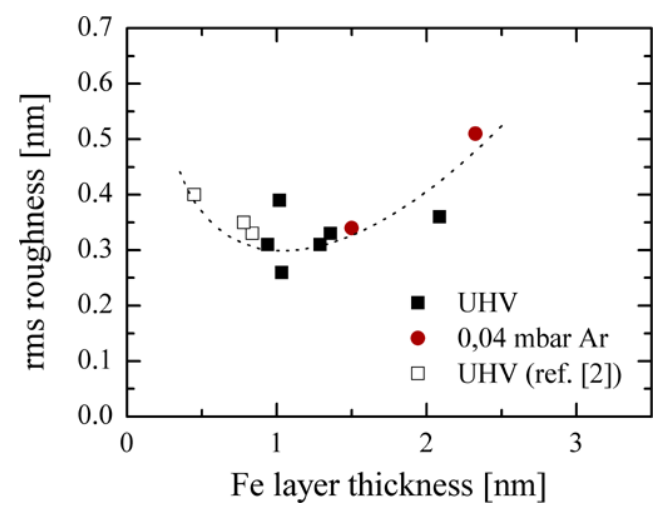

Fig. 4 Interface roughness of the $\mathrm{MgO} / \mathrm{Fe}$ multilayers of Fig. 3 vs. $\mathrm{Fe}$ layer thickness, and results taken from Ref. [2]

curves with scattering angle, the Kiessig fringes as well as the Bragg reflections can be reproduced by the corresponding simulations with high accuracy. Furthermore, two measurements were shown for a deposition in 0.04 mbar of $\mathrm{Ar}$ atmosphere. Using this background pressure during deposition, the energy of the deposited particles can be reduced as earlier shown [7]. The RMS roughnesses are (within the measuring accuracy) identical for both interfaces. They are summarized in Fig. 4, together with earlier results of Fuhse et al. [2], vs. Fe layer thickness. Obviously, with increasing Fe layer thickness the interface roughness first decreases, reaches a minimum at a $\mathrm{Fe}$ thickness of about $1 \mathrm{~nm}$ and then increases again. It should be noted that obviously the reduction of the kinetic energy of the deposited particles has almost no effect on the interface roughness.

In order to understand, at which growth state of the $\mathrm{Fe}$ layers the lowest interface roughness is obtained, in situ

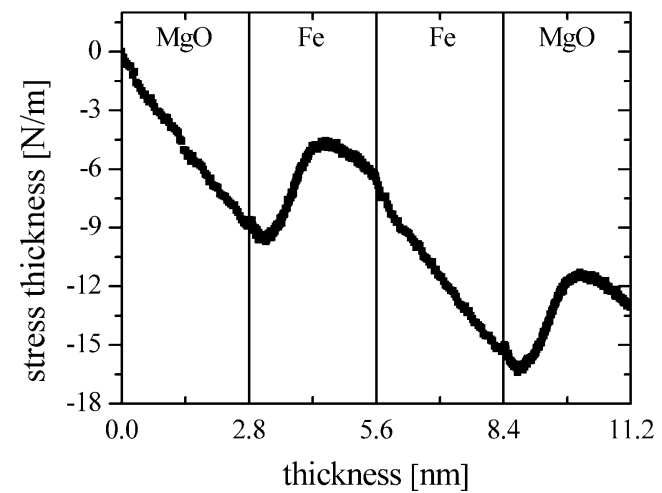

Fig. 5 Stress thickness vs. film thickness during laser deposition of a $\mathrm{Fe} / \mathrm{MgO}$ multilayer. A section of two layer periods is shown

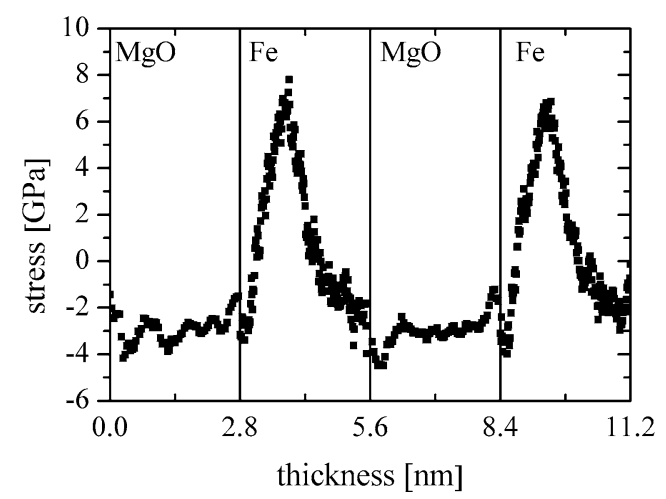

Fig. 6 In-situ stress measurements during laser deposition of a $\mathrm{Fe} / \mathrm{MgO}$ multilayer with 20 periods. A section of two layer periods is shown

stress measurements were performed during laser deposition of a $\mathrm{Fe} / \mathrm{MgO}$ multilayer with 20 periods. A section of two layer periods of the measurements is shown in Fig. 5. It can be followed that the stress curves are different for $\mathrm{MgO}$ and $\mathrm{Fe}$, respectively, but completely reproducible for both periods (and also for the 18 other periods, not shown here). As can be followed in the figure, the stress thickness decreases linearly with increasing $\mathrm{MgO}$ thickness. The constant slope of this curve corresponds to a compressive stress of about $-3 \mathrm{GPa}$ (see Fig. 6), which can be explained by shot-peening effects [13] due to energetic particles hitting the film surface, as typical during laser deposition in ultrahigh vacuum [14]. This kind of stress is representative for layer-by-layer growth of $\mathrm{MgO}$ on $\mathrm{Fe}$. When depositing $\mathrm{Fe}$ on top of $\mathrm{MgO}$, first compressive stress is observed, which then tends to tensile stress and again to compressive stress. The compressive-to-tensile transition is a clear indication for island growth in these laser deposited multilayers [15, 16], as expected from the differences in the surface energies of $\mathrm{Fe}$ and $\mathrm{MgO}$, and for instance also observed in evaporated films by Floro et al. [17]. The complex behavior of the stress thickness curve can be explained as follows. The first decrease in the stress thickness curve is called "capillary- 
induced" growth stress [18] and can be understood in the following way. Due to surface tension the lattice parameters of small grains are always smaller than the bulk value and size dependent. With rising grain size (and increasing film thickness) the lattice parameters increase to their equilibrium values leading to compressive stress as observed. The compressive-to-tensile transition is attributed to island impingement and coalescence, when the film is almost covered by the new component (in our case Fe). If then neighboring islands are within close proximity, they stretch toward each other and form a grain boundary to reduce the surface energy with expense of strain energy [19]. This so-called "island zipping" is accompanied with the formation of tensile stress. According to Seel et al. [16] the maximum tensile stress (in our case of about $7 \mathrm{GPa}$ ) is achieved when coalescence within the film has appeared and the $\mathrm{MgO}$ surface is almost covered by Fe. In our $\mathrm{MgO} / \mathrm{Fe}$ multilayer this is the case at a layer thickness of about $1 \mathrm{~nm}$ in agreement with results from Ref. [20]. For even higher thicknesses, when no additional stress due to island zipping occurs, the measured stress becomes compressive again due to shot-peening effects, now dominating the film stress.

Thus, at the Fe thickness of $1 \mathrm{~nm}$, where the interface roughness of the multilayers is minimized, island zipping processes within the Fe layers are maximal and the Fe layer is mostly closed. The $\mathrm{MgO}$ layers grown in layer-by-layer mode more or less keep the roughness of the Fe layers on the same level and probably smoothen out at least the high spatial frequencies. In this way, formation of cumulative roughness can be prevented.

\section{Conclusions}

In summary, all the results on $\mathrm{MgO} / \mathrm{Fe}$ multilayers indicate that the roughness of multilayers with large difference in surface energy, where one component grows in island growth mode and the other one in layer-by-layer mode, can be minimized and cumulative roughness can be prevented. For this, the layer of the island former has to be chosen with a thickness, where the layer is closed and island zipping processes are mostly completed. Within this layer, roughening due to island growth and smoothing by island zipping simultaneously take place. To determine this "optimal thickness", in-situ stress measurements as performed in this work are one method of choice. Here the point of maximal tensile stress determines the thickness of the island former with lowest interface roughness. For different materials, this value should depend on the size of the islands formed and thus on the diffusivity of the atoms on the underlying component. Additionally, this second component (here $\mathrm{MgO}$ ) eventually leads to a further smoothening of the surface because of its lower surface free energy. With the following layer of the first component (here Fe) growing in VolmerWeber island growth mode the whole process starts again.

Acknowledgement This work was supported by the Deutsche Forschungsgemeinschaft SFB602.

Open Access This article is distributed under the terms of the Creative Commons Attribution Noncommercial License which permits any noncommercial use, distribution, and reproduction in any medium, provided the original author(s) and source are credited.

\section{References}

1. M. Tolan, X-ray Scattering from Soft-Matter Thin Films: Materials Science and Basic Research. Springer Tracts in Modern Physics, vol. 148 (Springer, Berlin/New York, 1999)

2. C. Fuhse, H.U. Krebs, S. Vitta, G.A. Johansson, Appl. Opt. 43, 6265 (2004)

3. S. Yuasa, T. Nagahama, A. Fukushima, Y. Suzuki, K. Ando, Nat. Mater. 3, 868 (2004)

4. L.Z. Mezey, J. Giber, Jpn. J. Appl. Phys., Part 1 21, 1569 (1982)

5. M. Volmer, A. Weber, Z. Phys. Chem. 119, 277 (1925)

6. H.U. Krebs, O. Bremert, Appl. Phys. Lett. 62, 2341 (1993)

7. K. Sturm, H.-U. Krebs, J. Appl. Phys. 90, 1061 (2001)

8. T. Scharf, J. Faupel, K. Sturm, H.U. Krebs, J. Appl. Phys. 94, 4273 (2003)

9. G.G. Stoney, Proc. R. Soc. Lond. Ser. A 82, 172 (1909)

10. W.H. Butler, X.G. Zhang, T.C. Schulthess, J.M. MacLaren, Phys. Rev. B 63, 054416 (2001)

11. H.L. Meyerheim, R. Popescu, J. Kirschner, N. Jedrecy, M. Sauvage-Simkin, B. Heinrich, R. Pinchaux, Phys. Rev. Lett. 87, 076102 (2001)

12. D.L. Windt, Comput. Phys. 12, 360 (1998)

13. H. Windischmann, J. Appl. Phys. 62, 1800 (1987)

14. H.U. Krebs, Int. J. Non-Equilib. Process. 10, 3 (1997)

15. W.D. Nix, B.M. Clemens, J. Mater. Res. 14, 3467 (1999)

16. S.C. Seel, C.V. Thompson, S.J. Hearne, J.A. Floro, J. Appl. Phys. 88, 7079 (2000)

17. J.A. Floro, S.J. Hearne, J.A. Hunter, P. Kotula, E. Chason, S.C. Seel, C.V. Thompson, J. Appl. Phys. 89, 4886 (2001)

18. R.C. Cammarata, Prog. Surf. Sci. 46, 1 (1994)

19. R.W. Hoffman, Thin Solid Films 34, 185 (1976)

20. A. Garcia-Garcia, A. Vovk, J.A. Pardo, P. Strichovanec, C. Magen, E. Snoeck, P.A. Algarabel, J.M. De Teresa, L. Morellon, M.R. Ibarra, J. Appl. Phys. 105, 063909 (2009) 